\title{
Overexpression of miR-30c-5p reduces cellular cytotoxicity and inhibits the formation of kidney stones through ATG5
}

\author{
XIN WANG ${ }^{1}$, YANAN ZHANG ${ }^{1}$, SHUAI HAN $^{1}$, HONGSHEN CHEN $^{2}$, \\ $\mathrm{CHEN} \mathrm{CHEN}^{1}$, LINGLING $\mathrm{JI}^{1}$ and BIHU GAO ${ }^{1}$ \\ Departments of ${ }^{1}$ Nephrology and ${ }^{2}$ Breast and Thyroid Surgery, \\ Zhongshan Hospital of Dalian University, Dalian, Liaoning 116001, P.R. China
}

Received July 12, 2019; Accepted November 5, 2019

DOI: $10.3892 /$ ijmm.2019.4440

\begin{abstract}
MicroRNAs (miRNAs or miRs) are critical regulators in various diseases. In the current study, the role of miR-30c-5p in the formation of sodium oxalate-induced kidney stones was investigated. For this purpose, human renal tubular epithelial cells (HK-2 cells) were incubated with sodium oxalate at the concentrations of 100, 250, 500, 750 and $1,000 \mu \mathrm{M}$. Cell viability and the miR-30c-5p expression level were respectively measured by CCK- 8 assay and RT-qPCR. After separately transfecting miR-30c-5p mimic and inhibitor into the HK-2 cells, the cell apoptotic rate, the levels of mitochondrial membrane potential (MMP) and ROS were determined by flow cytometry. The levels of oxidative stress indicators [lactate dehydrogenase (LDH), malondialdehyde (MDA), superoxide dismutase (SOD) and catalase (CAT)] were determined using commercial kits. Crystal-cell adhesion assay was performed to evaluate the crystal adhesion capacity in vitro. miR-30c-5p binding at autophagy related 5 (ATG5) was predicted by TargetScan7.2 and further verified by dual-luciferase reporter assay. Rescue experiments were performed to confirm the molecular mechanisms underlying sodium oxalate-induced kidney formation in HK-2 cells. The results revealed that sodium oxalate decreased the viability of HK-2 cells in a concentration-dependent manner, and that miR-30c-5p expression was significantly downregulated by exposure to $750 \mu \mathrm{M}$ sodium oxalate. In addition, the increase in cell apoptosis and crystal number, and the upregulated levels of LDH, MDA and ROS were reversed by the overexpression of miR-30c-5p. Moreover, the overexpression of miR-30c-5p upregulated the levels of SOD, CAT and MMP induced by sodium oxalate. ATG5 was directly regulated by miR-30c-5p, and the inhibition of cell cytotoxicity and crystal-cell adhesion
\end{abstract}

Correspondence to: Dr Bihu Gao, Department of Nephrology, Zhongshan Hospital of Dalian University, 6 Jiefang Street, Zhongshan, Dalian, Liaoning 116001, P.R. China

E-mail: gaobihu@126.com

Key words: kidney stones, apoptosis, oxidative stress, miR-30c-5p, autophagy related 5 induced by miR-30c-5p mimic was blocked by ATG5. These data indicated that the overexpression of miR-30c-5p alleviated cell cytotoxicity and crystal-cell adhesion induced by sodium oxalate through ATG5. Thus, the current study provides a better understanding of the role of miR-30c-5p in sodium oxalate-induced kidney stones.

\section{Introduction}

Kidney stone formation is a common disease with a high morbidity (1). Kidney stones can lead to the development of severe diseases such as hydronephrosis, renal function impairment or insufficiency if active treatment is not undertaken. In addition, kidney stones have a high occurrence rate (2). Calcium oxalate $(\mathrm{CaOx})$-induced kidney stones, which are the most common types of kidney stones, account for approximately $60 \%$ of all cases of kidney stones in China (3). CaOx-induced kidney stones can be formed by crystal deposits in tubular epithelial cells, a high level of reactive oxygen species (ROS) and the subsequent inflammatory response. Oxidative stress has been recognized as a major factor contributing to the pathogenesis of kidney injury and the formation of kidney stones (4). A previous study also demonstrated that oxidative stress produced by a high concentration of oxalate can lead to tubular injury and stone formation (5).

There is evidence to indicate that renal tubular cell injury induced by $\mathrm{CaOx}$ plays a key role in the formation of kidney stones (6); specifically, the increased expression of cellular apoptosis- and apoptosis-associated genes induced by $\mathrm{CaOx}$ contribute to kidney stone formation (7). $\mathrm{CaOx}$ crystals also induce autophagy through the activation of the ROS pathway in HK-2 cells (8). Randall plaques (RPs) are considered a factor contributing to the formation of idiopathic $\mathrm{CaOx}$-induced kidney stones. In a previous study, in a model of RP-CaOx-induced kidney stones, differentially expressed genes were shown to be associated with the activation of mitogen-activated protein kinase, the Akt/phosphatidylinositol 3-kinase pathway and pro-inflammatory cytokines that can cause renal injury and oxidative stress, which points to their critical roles in the development of $\mathrm{CaOx}$-induced kidney stones (9). Another study also demonstrated that the ROS/Akt/p38 MAPK signaling pathway is activated in the calcium oxalate monohydrate (COM)-induced disruption of 
tight junction and causes renal cell injury and kidney stone formation (10). Epithelial-to-mesenchymal transition (EMT) induced by $\mathrm{CaOx}$ crystals and oxalate in proximal tubular cells has also been shown to lead to kidney injury (11). Thus, it was speculated that multiple pathways are involved in cell damage induced by $\mathrm{CaOx}$.

MicroRNAs (miRNAs or miRs) are critical regulators in various diseases, including kidney stones (12). Claudin-14 gene expression is a key regulator of renal $\mathrm{Ca}(2+)$ homeostasis. It has previously been reported that miRNAs can directly regulate the expression of Claudin-14 in human kidney diseases, including nephrolithiasis $(13,14)$. Recently, an integrative analysis of miRNA-mRNA expression profiles in $\mathrm{CaOx}$-induced kidney stones suggested that miRNAs play a critical role in the development of kidney stones (15). Serum and urinary levels of miR-155 are closely related to inflammatory cytokine levels in patients with nephrolithiasis (16). However, the role of miRNAs in the pathophysiology of nephrolithiasis has been less extensively reported. Recent studies have demonstrated that miR-30c-5p (miR-30c) is related to kidney injury induced by ischemia-reperfusion $(\mathrm{I} / \mathrm{R})(17,18)$. miR-30c has been shown to regulate the apoptosis of renal tubular epithelial cells by targeting Bnip3L and Hspa5 (19). miR-30c can affect the pathogenesis of diabetic nephropathy by targeting CTGF. Three miR-30 family members, including miR-30c are biomarkers and therapeutic candidates for acute kidney injury (20). Therefore, it was speculated that miR-30c may be involved in the development of renal injury and in the formation of kidney stones.

In this study, the authors aimed to investigate the role of miR-30c-5p in sodium oxalate-induced renal tubular epithelial injury, in order to provide a better understanding of the role of miRNAs in the pathogenesis of kidney stone formation.

\section{Materials and methods}

Cells, cell culture and treatment. Human renal tubular epithelial cells (HK-2 cells) were obtained from the American Type Culture Collection (ATCC) and cultured in DMEM-F12 (11320082, Gibco; Thermo Fisher Scientific) containing 10\% FBS (16140071, Invitrogen; Thermo Fisher Scientific) and 1\% penicillin/streptomycin (15070063, Gibco; Thermo Fisher Scientific) at $37^{\circ} \mathrm{C}$ with $5 \% \mathrm{CO}_{2}$. Sodium oxalate $(\mathrm{O} 0136$, Sigma) was diluted to $100,250,500,750$ and $1,000 \mu \mathrm{M}$ by double distilled water. The cells were seeded in a 6-well plate (1x10 $10^{6}$ cells/well) or 96 -well plate $\left(2 \times 10^{4}\right.$ cells/well $)$ as needed. Subsequently, the cells were incubated with the oxalate solution at various concentrations as described above, and those in the control group were treated with an equal volume of double distilled water. Following incubation for 3 days at $37^{\circ} \mathrm{C}$ with $5 \% \mathrm{CO}_{2}$, the medium was refreshed in each well.

$C C K-8$ assay. The cells were stimulated by various concentrations $(100,250,500,750$ and $1,000 \mu \mathrm{M})$ of oxalate for 3 days in a 96 -well plate $\left(2 \times 10^{4}\right.$ cells/well) and washed with PBS twice. Subsequently, $10 \mu 1$ CCK-8 solution (70-CCK801, MultiSciences) mixed with $100 \mu \mathrm{l}$ fresh medium were added to each well. Following incubation of the cells at $37^{\circ} \mathrm{C}$ in the dark for 4 days, the absorbance value at a wavelength of $450 \mathrm{~nm}$ was detected using the SpectraMax Plus 384 Microplate Reader
(PLUS 384, Molecular Devices). A $10 \mu \mathrm{l} \mathrm{CCK-8} \mathrm{solution}$ mixed with $100 \mu \mathrm{l}$ of the medium served as a negative control.

$R N A$ isolation and $R T-q P C R$. The cells were washed with PBS and treated with TRIzol regent (15596018, Invitrogen; Thermo Fisher Scientific) at $4^{\circ} \mathrm{C}$ for $2 \mathrm{~min}$. The RNA was then isolated by chloroform and islpropanol at $4^{\circ} \mathrm{C}$. A NanoDrop 8000 spectrophotometer (ND-8000-GL, Thermo Fisher Scientific) was used to determine the concentration of the RNA. The RNA was then reverse transcribed into cDNA using the PrimeScript ${ }^{\mathrm{TM}}$ II 1st Strand cDNA Synthesis kit (6210B, Takara). SYBR ${ }^{\circledR}$-Green PCR Master Mix (4312704, ABI) and the Bio-Rad CFX 96 Touch Real-Time PCR Detection System (1855196, Bio-Rad) were used for RT-qPCR. The sequences of the primers were as follows: ATG5 forward, 5'-AAGCAA CTCTGGATGGGATT-3' and reverse, 5'-GCAGCCACAGGA CGA-3' (21); and GAPDH forward, 5'-AGGTCGGTGTGA ACGGATTTG-3 and reverse, 5'-GGGGTCGTTGATGGC AACA-3'. The parameters of RT-qPCR were set as follows: Pre-denaturation at $95^{\circ} \mathrm{C}$ for $5 \mathrm{~min}$, followed by denaturation at $95^{\circ} \mathrm{C}$ for $30 \mathrm{sec}$, annealing at $60^{\circ} \mathrm{C}$ for $30 \mathrm{sec}$ and extension at $72^{\circ} \mathrm{C}$ for $30 \mathrm{sec}$. The $2^{-\Delta \Delta \mathrm{Cq}}$ method (22) was used to calculate the relative expression. For the quantification of miR-30c-5p, the One-Step miRNA RT kit (D1801, HaiGene) was used to prepare the cDNA. SYBR-Green qPCR kits (AP01370 and AP02055, HaiGene, China) were used for the RT-qPCR of miR-30c-5p and U6 snRNA. The parameters in RT-qPCR were set as follows: At $95^{\circ} \mathrm{C}$ for $5 \mathrm{~min}, 40$ cycles at $95^{\circ} \mathrm{C}$ for $15 \mathrm{sec}$, at $60^{\circ} \mathrm{C}$ for $30 \mathrm{sec}$, and $70^{\circ} \mathrm{C}$ for $10 \mathrm{sec}$. The relative expression were calculated by $2^{-\Delta \Delta \mathrm{Cq}}$ method (22).

Cell transfection. miR-30c-5p mimic (miR1160713102113-1-5), miR-30c-5p inhibitor (miR20000244-1-5), negative control oligos for mimics (miR0190513015853) and inhibitors (miR2N0000003-1-5) were synthesized by Ribobio Co., Ltd. ATG5 was synthesized by Tsingke Co., Ltd. and cloned into the pcDNA 3.1 vector (V79020, Invitrogen; Thermo Fisher Scientific). The cells were cultured at $4 \times 10^{5}$ cells/well in 6 -well plates and respectively transfected with 100 pmoles of miRNA mimic or inhibitor using Lipofectamine ${ }^{\circledR} 2000$ (11668019, Invitrogen; Thermo Fisher Scientific) at room temperature after the cells reached 50-60\% confluence. Following incubation for $24 \mathrm{~h}$ at $37^{\circ} \mathrm{C}$, the cells were restored by the addition of fresh culture medium and collected for subsequent functional detections.

Cell apoptosis. The cell apoptotic rate was determined using the Annexin V-FITC/PI kit (70-AP101-100, MultiSciences). Briefly, the cells were cultured in a 6-well plate $\left(2 \times 10^{4}\right.$ cells/well) for $24 \mathrm{~h}$. Following trypsinization, the cells were collected by centrifugation at $450 \mathrm{x}$ g at $4^{\circ} \mathrm{C}$ for $5 \mathrm{~min}$ and then resuspended in $300 \mu \mathrm{l}$ of binding buffer and added with $5 \mu \mathrm{l}$ Annexin V-FITC solution. Following $15 \mathrm{~min}$ of incubation at room temperature in the dark, $5 \mu 1$ propidium iodide (PI) were added to the cells and incubated together for $5 \mathrm{~min}$. Finally, $200 \mu \mathrm{l}$ binding buffer were added to the cells. The cell apoptotic rate was determined using a FACSCalibur flow cytometer (342973, BD Biosciences) and analyzed using BD FACSCanto ${ }^{\mathrm{TM}}$ system software v2.4 (646602, BD Biosciences). 
ROS assay. ROS was measured using the Total Reactive Oxygen Species (ROS) assay kit (S0033, Beyotime). Briefly, the cells were seeded in 6-well plates at a density of $8 \times 10^{4}$ cells/well and collected by trypsinization at $37^{\circ} \mathrm{C}$ for $2 \mathrm{~min}$ and centrifugation at $500 \mathrm{x}$ g for $4 \mathrm{~min}$ at $4^{\circ} \mathrm{C}$. The cells were then incubated with DCFH-DA (at a final concentration of $10 \mu \mathrm{M}$ ) for $30 \mathrm{~min}$ at $37^{\circ} \mathrm{C}$. After washing the cells 3 times with PBS solution, the fluorescence intensity of the cells was measured by flow cytometry (342973, BD Biosciences).

Mitochondrial membrane potential (MMP). MMP (also known as $\Delta \Psi \mathrm{m})$ was assessed using JC-1 fluorescent dye (C2006, Beyotime). The cells were then cultured at $8 \times 10^{4}$ cells $/$ well in 6-well plates and incubated with $10 \mu \mathrm{l}$ of $200 \mu \mathrm{M} \mathrm{JC}-1$ (final concentration of $2 \mu \mathrm{M}$ ) at $37^{\circ} \mathrm{C}$ in $5 \% \mathrm{CO}_{2}$ for $30 \mathrm{~min}$. Subsequently, the cells were washed twice with $1 \mathrm{ml}$ cooled 1X JC-1 buffer. The cells were then centrifuged at $600 \mathrm{x}$ g for $5 \mathrm{~min}$ at $4^{\circ} \mathrm{C}$, and analyzed on a flow cytometer (342973, BD Biosciences) at a $525 \mathrm{~nm}$ wavelength and $490 \mathrm{~nm}$ wavelength for the detection of JC-1 polymers and monomers, respectively.

Determination of lactate dehydrogenase $(L D H)$. The cells were cultured in 96-well plates, and the medium in each well was then collected and centrifuged at $1,000 \times \mathrm{g}$, at $4^{\circ} \mathrm{C}$ for $10 \mathrm{~min}$. The LDH in the supernatant was measured using a Cytotoxicity Detection kit (LDH, 11644793001). Subsequently, $100 \mu 1$ reaction reagent were mixed with $100 \mu \mathrm{l}$ supernatant and incubated for $30 \mathrm{~min}$ at room temperature. The absorbance was then read at $490 \mathrm{~nm}$ using a multimode reader (PLUS 384, Molecular Devices). The data were normalized to those of the cells in control group.

Measurement of oxidative stress. The level of malondialdehyde (MDA) was determined using the Lipid Peroxidation (MDA) assay kit (MAK085, Sigma). Briefly, 1×106 cells were homogenized by $300 \mu \mathrm{l}$ MDA lysis buffer containing $3 \mu \mathrm{l}$ BHT. The samples were centrifuged at $13,000 \times \mathrm{g}, 4^{\circ} \mathrm{C}$ for $10 \mathrm{~min}$. A total of $200 \mu \mathrm{l}$ of the supernatant was mixed with $600 \mu \mathrm{l}$ of the TBA solution, and following incubation at $95^{\circ} \mathrm{C}$ for $60 \mathrm{~min}$, the mixture was cooled down on ice for $10 \mathrm{~min}$. Subsequently, $200 \mu \mathrm{l}$ of each reaction mixture was pipetted into a 96-well plate and analyzed at a $532 \mathrm{~nm}$ wavelength using a multimode reader (PLUS 384, Molecular Devices).

In addition, the activities of the antioxidant enzymes, super oxide dismutase (SOD) and catalase (CAT), were measured using the Total Superoxide Dismutase assay kit (S0109, Beyotime) and Catalase assay kit (S0051, Beyotime). The cells were cultured at $8 \times 10^{4}$ cells/well in 6 -well plates and then homogenized in $05 \mathrm{ml}$ buffer solution. The cells were centrifuged at $600 \mathrm{x} \mathrm{g}, 4^{\circ} \mathrm{C}$ for $10 \mathrm{~min}$ to measure the activities of SOD and CAT in the supernatants. For SOD activity, $20 \mu \mathrm{l}$ homogenates were mixed with $160 \mu \mathrm{l}$ NBT reagent and $20 \mu \mathrm{l}$ reaction reagent at $37^{\circ} \mathrm{C}$ and held for $30 \mathrm{~min}$. An equal volume of detection buffer mixed with $160 \mu \mathrm{l}$ NBT reagent and $20 \mu \mathrm{l}$ reaction reagent served as the blank control. The level of SOD was determined at a $560 \mathrm{~nm}$ wavelength using a multimode reader (PLUS 384, Molecular Devices). For CAT activity, $10 \mu \mathrm{l}$ homogenates were mixed with $10 \mu 1$ hydrogen peroxide reagent and $30 \mu \mathrm{l}$ hydrogen peroxide detection buffer. Subsequently, $40 \mu 1$ hydrogen peroxide detection buffer mixed with $10 \mu \mathrm{l}$ of $250 \mathrm{mM}$ hydrogen peroxide reagent served as the blank control. Following incubation at $25^{\circ} \mathrm{C}$ for $5 \mathrm{~min}, 450 \mu \mathrm{l}$ of stopping solution were added to the mixture to terminate the reaction, and the mixture was then detected at a $240 \mathrm{~nm}$ wavelength using a multimode reader (PLUS 384, Molecular Devices).

Crystal-cell adhesion assay. The treated cells were cultured in a 6-well plate. As previously described, the cells with full confluence were incubated in DMEM containing $100 \mu \mathrm{g} / \mathrm{ml}$ calcium oxalate monohydrate (COM, C0350000, Sigma) for $10 \mathrm{~min}$ at $37^{\circ} \mathrm{C}$ in a humidified atmosphere with $5 \% \mathrm{CO}_{2}(23)$. The cells were then washed by PBS twice to remove residual COM crystals. The images of the crystals were captured under a microscope (ECLIPSE TS100, Nikon). A total of 10 randomized high-power fields per well were selected and the numbers of adherent crystals in each field were counted. The representative images were selected, at the same scale, and the area of the field selected by the square was equal. The crystal numbers in different groups were standardized with the control group.

Bioinformatics and dual-luciferase reporter assay. TargetScan7.2 (http://www.targetscan.org/vert_72/) was applied to predict the target gene of miR-30c-5p. DNA sequences of ATG5-WT and ATG5-MUT were obtained from Tsingke Co., Ltd. and separately constructed into the luciferase reporter gene vector (pmirGLO, E1330, Promega) to construct luciferase reporter plasmids. Renilla luciferase vector (E6911, Promega, USA) was co-transfected into the cells as a reporter control. Briefly, the cells cultured in 96-well plates were transfected with luciferase reporter plasmid $(0.05 \mu \mathrm{g} /$ well $)$ or co-transfected with luciferase reporter plasmid and miR-30c-5p mimic (15 nM). Following transfection for $24 \mathrm{~h}$, the cells were analyzed for luciferase activity using the Dual-Glo ${ }^{\circledR}$ Luciferase assay system (E2920, Promega) and Microplate Luminometer (11300010, Berthold). The luciferase activity was normalized by firefly luciferase activity in comparison with Renilla luciferase activity. For each transfection, the luciferase activity was averaged from 6 replicates.

Statistical analysis. The data are presented as the means \pm SD. Differences between 2 groups were assessed by one-way ANOVA, followed by Dunnett's post hoc test (version 19.0 software, SPSS, Inc.). A $\mathrm{P}<0.05$ was considered to indicate a statistically significant difference.

\section{Results}

Effect of miR-30c-5p on oxalate-induced cytotoxicity in $H K-2$ cells. The viability of HK-2 cells stimulated by oxalate at concentrations of $0,100,250,500,750$ and $1,000 \mu \mathrm{M}$ was determined, and the results revealed that oxalate reduced cell viability in a concentration-dependent manner (Fig. 1A). The results of RT-qPCR also revealed that the expression level of miR-30c-5p was downregulated in HK-2 cells exposed to $750 \mu \mathrm{M}$ oxalate (Fig. 1B).

Furthermore, miR-30c-5p mimic and inhibitor were successfully transfected into the HK-2 cells to upregulate and 
A

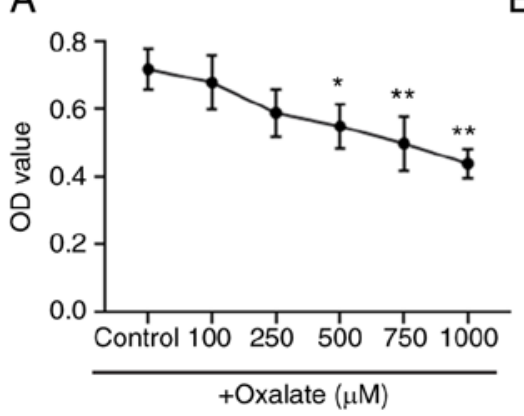

B

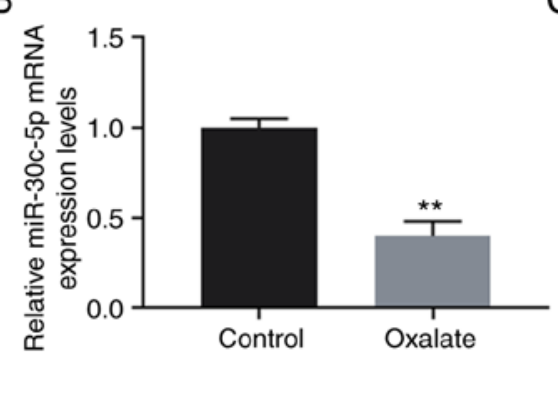

C

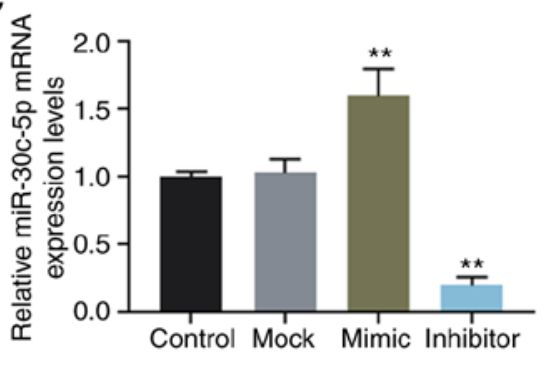

Figure 1. Effects of oxalate on the viability of and expression of miR-30c-5p in HK-2 cells. (A) Viability of HK-2 cells incubated with oxalate at the concentrations of $0,100,250,500,750$ and $1,000 \mu \mathrm{M}$ was measured by CCK-8 assay. (B) The level of miR-30c-5p in the HK-2 cells exposed to oxalate (750 $\mu \mathrm{M})$ was measured by RT-qPCR. ${ }^{*} \mathrm{P}<0.05$ and ${ }^{* *} \mathrm{P}<0.001$ vs. control. (C) The level of miR-30c-5p in HK-2 cells was measured by RT-qPCR. ${ }^{* *} \mathrm{P}<0.001$ vs. mock. Control, transfection with control mimic and control inhibitor; mock, transfection with nothing; mimic, miR-30c-5p mimic; inhibitor, miR-30c-5p inhibitor.

downregulate the level of miR-30c-5p, respectively (Fig. 1C). The results of flow cytometry indicated that oxalate increased the apoptotic rate of the HK-2 cells, which however, was reversed by transfection with miR-30c-5p mimic and was enhanced by transfection with miR-30c-5p inhibitor, respectively (Fig. 2A and B). Oxalated stimulation also increased the activities of LDH and MDA, and these effects were reverse by transfection with miR-30c-5p mimic and aggravated by transfection with miR-30c-5p inhibitor (all $\mathrm{P}<0.001$, Fig. 2C and D). However, the changes in SOD and CAT activities exhibited opposite results (all $\mathrm{P}<0.001$, Fig. 2D). $\mathrm{JC}-1$ is used as an indicator of MMP $(\Delta \Psi \mathrm{m})$ in a variety of cell types, and when the $\Delta \Psi \mathrm{m}$ is high, JC-1 accumulates in the mitochondrial matrix and forms polymers, while at a low $\Delta \Psi \mathrm{m}, \mathrm{JC}-1$ is unable to accumulate in the mitochondrial matrix and thus forms monomers. JC-1 polymers and monomers can be respectively detected at a wavelength of 585/590 and 514/529 nm. In this study, the levels of ROS and MMP were determined by flow cytometry, and the results revealed that the increase in ROS production and the decrease in MMP induced by oxalate were reversed by the overexpression of miR-30c-5p, but were enhanced by the inhibition of miR-30c-5p (Fig. 2E and F). Crystal-cell adhesion assay also demonstrated that the crystal number increased significantly in the HK-2 cells exposed to oxalated, and this increase was abolished by transfection with miR-30c-5p mimic, whereas it was promoted by transfection with miR-30c-5p inhibitor (all $\mathrm{P}<0.001$, Fig. 3).

ATG5 is directly targeted and regulated by miR-30c-5p. TargetScan7.2 was used to predict the binding site for miR-30c-5p at position 707-714 of the ATG5 3'UTR (Fig. 4A), and dual-luciferase reporter assay was performed to verify the association between miR-30c-5p and ATG5. The results revealed that the luciferase activity of the HK-2 cells transfected with ATG5-WT reporter plasmid was significantly decreased by miR-30c-5p $(\mathrm{P}<0.001)$, while no obvious change was observed in the cells transfected with the ATG5-MUT reporter plasmid (Fig. 4B). The results of RT-qPCR demonstrated that the overexpression of miR-30c-5p decreased the expression level of ATG5, while ATG5 expression in the mimic + ATG5 group was significantly higher than that in the mimic + NC group (Fig. 4C).
miR $-30 c-5 p$ regulates the oxalate-induced cytotoxicity in $H K-2$ cells by targeting ATG5. Functional rescue experiments were performed to confirm the function of miR-30c-5p in targeting ATG5. Flow cytometry was carried out to determine the cell apoptotic rate and the levels of ROS and MMP in the HK-2 cells exposed to oxalate. Additionally, the relative activities of LDH, MDA, SOD and CAT were determined. The results demonstrated that the overexpression of ATG5 'rescued' the decrease in the cell apoptotic rate, the ROS level, the activities of LDH and MDA and crystal number, the increase in SOD and CAT activities and the upregulated level of MMP induced by transfection with miR-30c-5p mimic (all $\mathrm{P}<0.001$, Fig. 5). Crystal-cell adhesion assay was performed to determine the crystal-forming ability, and the data indicated that transfection with miR-30c-5p mimic reduced the crystal number in the HK-2 cells exposed to oxalate, whereas the overexpression of ATG5 reversed the effects induced by transfection with miR-30c-5p mimic (all $\mathrm{P}<0.001$, Fig. 6).

\section{Discussion}

Oxalate is an end product of metabolism, and a high level of oxalate can lead to hyperoxaluria and even in the formation of CaOx-induced kidney stones (24). In this study, it was found that oxalate at various concentrations led to a decrease in the viability of human renal tubular epithelial cells, and such a result was consistent with the findings of previous studies $(25,26)$. A previous study reported that miR-30c alleviated diabetic nephropathy via the Snail1/TGF- $\beta 1$ pathway (27). Of note, it was found that miR-30c-5p was downregulated by oxalate stimulation, suggesting that $\mathrm{miR}-30 \mathrm{c}-5 \mathrm{p}$ may be involved in oxalate-induced cell injury.

Apoptosis is a type of programmed cell death, and a previous study suggested that the reduction in cell viability induced by $\mathrm{CaOx}$ was associated with cell apoptosis (28). Moreover, cell injury induced by oxalate occurs due to apoptosis (29). In the early stages of apoptosis, phosphatidylserine (PS) is exposed outwards to the cell surface. FITC-labeled Annexin V selectively binds to PS and can be detected by flow cytometry. MMP is another indicator of apoptosis, and a low MMP $(\Delta \Psi \mathrm{m})$ causes JC-1 polymers to turn into monomers when apoptosis occurs. JC-1 monomers can be detected at a wavelength of 514/529 nm, while JC-1 

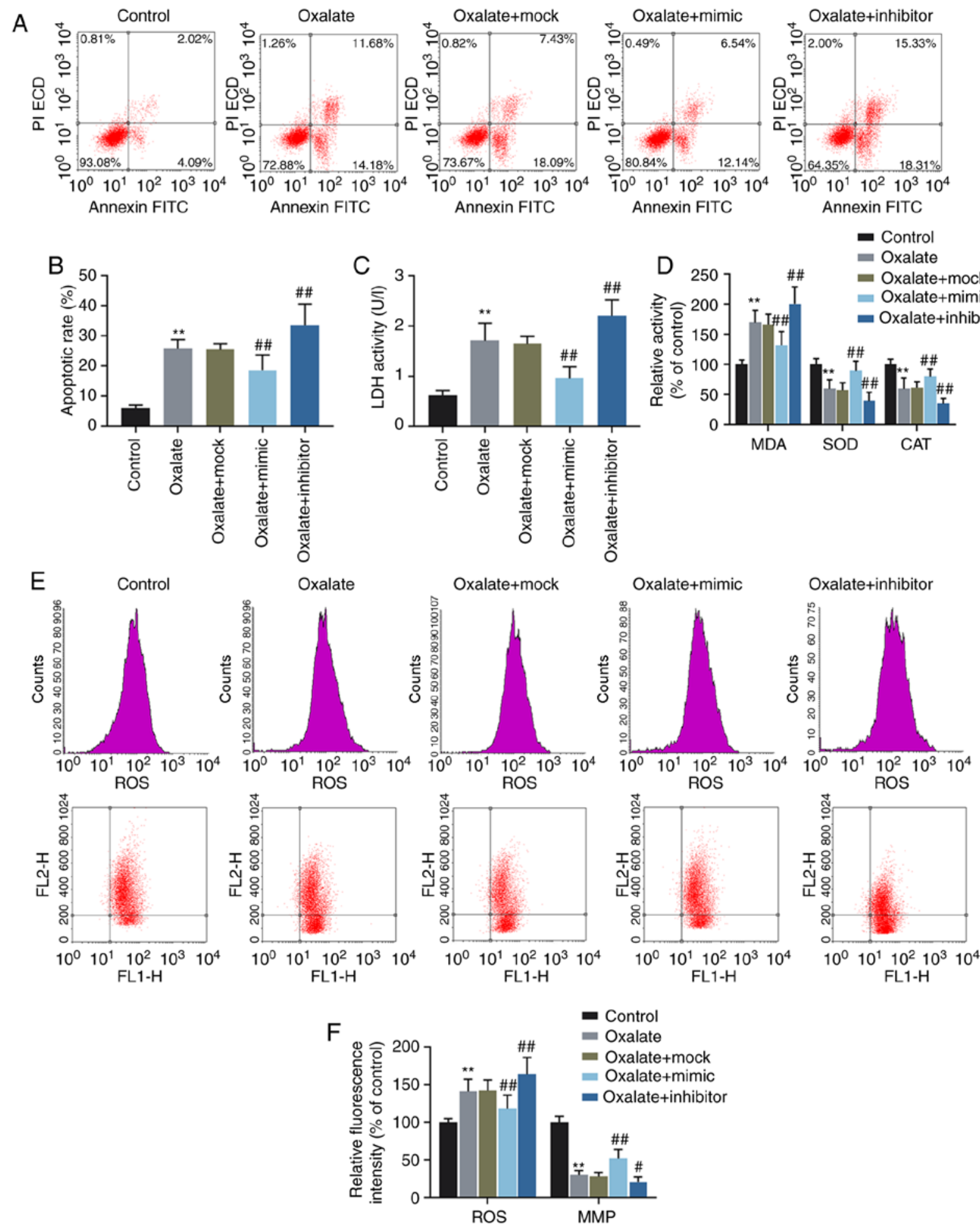

Figure 2. Effects of miR-30c-5p on cytotoxicity in HK-2 cells induced by oxalate. (A and B) The apoptotic rates of HK-2 cells determined by flow cytometry. (C) The LDH activity of HK-2 cells was determined by LDH assay. (D) The relative activities of MDA, SOD and CAT in HK-2 cells were determined by chemical colorimetry. (E and F) The levels of ROS (upper panel in row in 'E') and MMP (lower panel in 'E') in HK-2 cells were measured by flow cytometry. FL1-H, fluorescence intensity of JC-1 monomers. FL2-H, fluorescence intensity of JC-1 polymers. ${ }^{* *} \mathrm{P}<0.001$ vs. control; ${ }^{\#} \mathrm{P}<0.05$ and ${ }^{\# \#} \mathrm{P}<0.001$ vs. oxalate + mock. Control, transfection with control mimic and control inhibitor; oxalate, incubation with oxalate; oxalate + mock, incubation with oxalate and transfection reagent; oxalate + mimic, co-incubation with oxalate and miR-30c-5p mimic; oxalate + inhibitor, co-incubation with oxalate and miR-30c-5p inhibitor; MMP, mitochondrial membrane potential; LDH, lactate dehydrogenase; MDA, malondialdehyde; SOD, superoxide dismutase; CAT, catalase.

polymers can be detected at a wavelength of $585 / 590 \mathrm{~nm}$. Thus, this study also detected the apoptotic rate and MMP by flow cytometry. It has previously been reported that miR-30c is closely related to cell apoptosis. For example,
miR-30c regulates the apoptosis and proliferation of renal tubular epithelial cells (19), and a myocardial cell model (30). This study indicated that miR-30c-5p participates in cell apoptosis induced by oxalate. 
A

Control

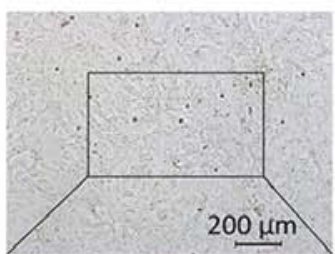

$100 \mu \mathrm{m}$
Oxalate

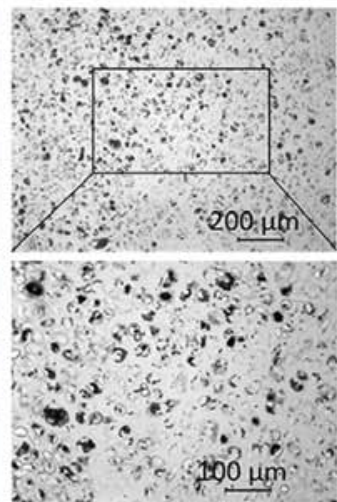

Oxalate+mock

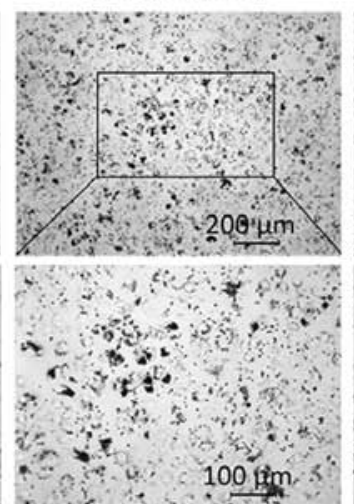

Oxalate+mimic

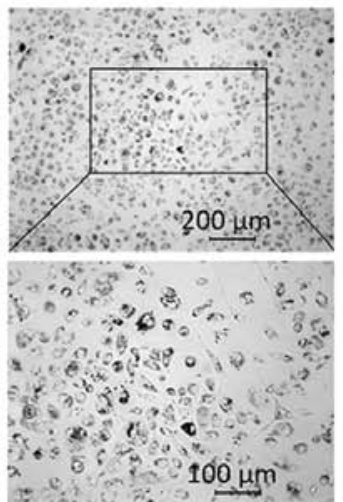

Oxalate+inhibitor

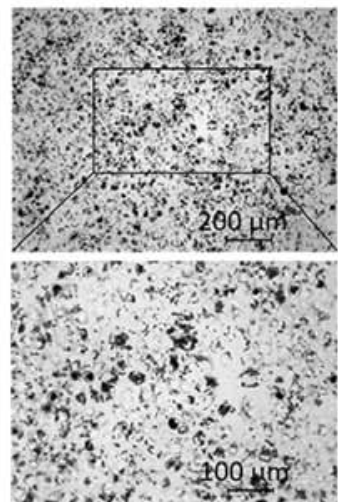

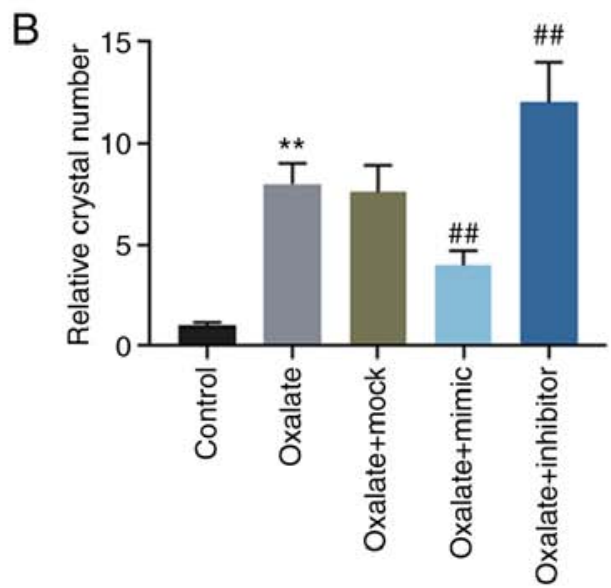

Figure 3. Effects of miR-30c-5p on crystal adhesion to HK-2 cells. (A) Crystal-cell adhesion assay results (A) and quantitative data for crystals adhering to cells (B) treated as described above. The black speckles in (A) indicate the oxalate crystals. Original magnification, $\mathrm{x} 200 .{ }^{* *} \mathrm{P}<0.001 \mathrm{vs}$. control; ${ }^{\# \#} \mathrm{P}<0.001$ vs. oxalate + mock. Control, transfection with control mimic and control inhibitor; oxalate, incubation with oxalate; oxalate + mock, incubation with oxalate and transfection regent; oxalate + mimic, co-incubation with oxalate and miR-30c-5p mimic; oxalate + inhibitor, co-incubation with oxalate and miR-30c-5p inhibitor.

A

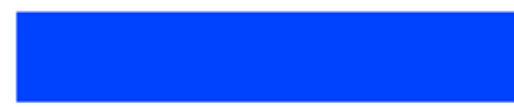

Position 707-714 of ATG5 3' UTR hsa-miR-30c-5p

\section{Predicted consequential pairing of target region (top) and} miRNA (bottom)

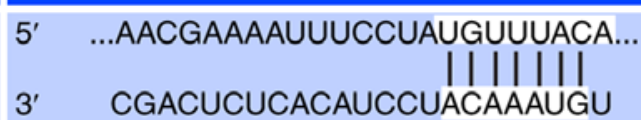

B

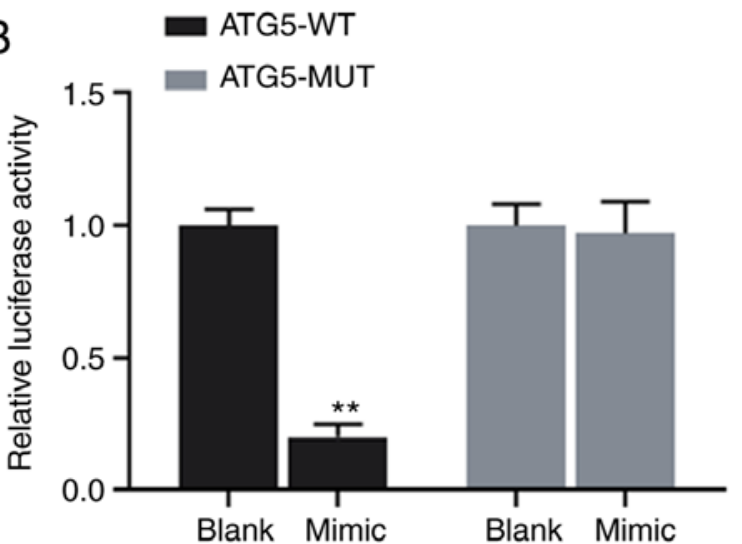

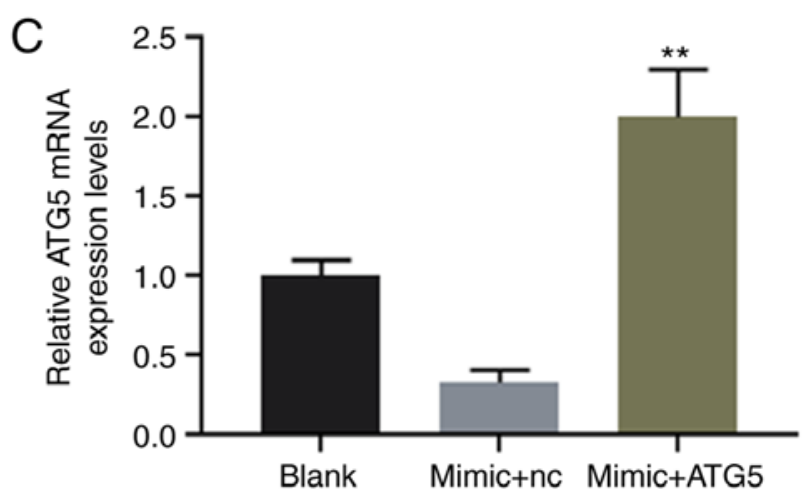

Figure 4. miR-30c-5p targets the 3'UTR of ATG5 and regulates its expression. (A) Potential target site for miR-30c-5p on the 3'UTR of ATG5 mRNA predicted by TargetScan7.2. (B) Dual-luciferase reporter assay was conducted to demonstrate the interactions between miR-30c-5p and 3' UTR of ATG5. ${ }^{* *} \mathrm{P}<0.001 \mathrm{vs}$. blank. (C) The levels of ATG5 affected by miR-30c-5p and overexpressed ATG5 were determined by RT-qPCR. ${ }^{* *} \mathrm{P}<0.001$ vs. mimic + NC; blank, transfection with nothing; mimic + NC, transfection with miR-30c-5p mimic and empty plasmid; mimic + ATG5, transfection with miR-30c-5p mimic and ATG5 overexpression plasmid. 

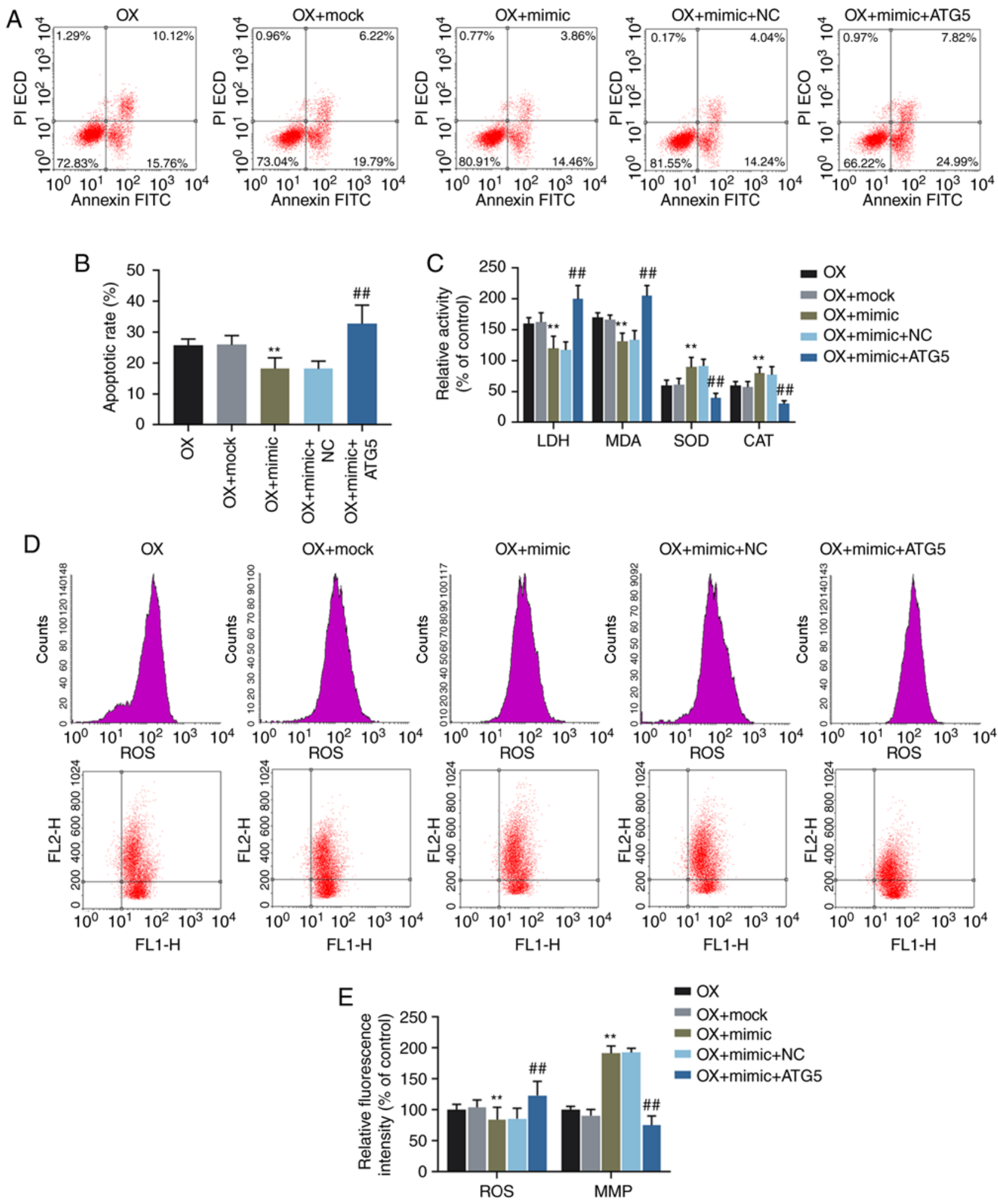

Figure 5. Effects of miR-30c-5p on oxalate-induced cytotoxicity via the regulation of ATG5. (A and B) Apoptotic rates of HK-2 cells were determined by flow cytometry. (C) The relative activities of LDH, MDA, SOD and CAT in HK-2 cells were determined by chemical colorimetry. (D and E) The levels of ROS (upper panel in 'D') and MMP (lower panel in 'D') in HK-2 cells were determined by flow cytometry. ${ }^{* *} \mathrm{P}<0.001$ vs. OX + mock; ${ }^{\# *} \mathrm{P}<0.001$ vs. OX + mimic + NC. OX, incubation with oxalate; OX + mock, incubation with oxalate and transfection reagent; OX + mimic, co-incubation with oxalate and miR-30c-5p mimic; oxalate + mimic + NC, co-incubation with oxalate, miR-30c-5p mimic and empty plasmid; OX + mimic + ATG5, co-incubation with oxalate, miR-30c-5p mimic and ATG5 overexpression plasmid. MMP, mitochondrial membrane potential.

It has been demonstrated that ROS are produced during $\mathrm{CaOx}$-induced nephrolithiasis (31). The production of ROS is controlled under normal conditions; however, it is increased when the conditions change, such as for example, a high concentration of oxalate and crystals of $\mathrm{CaOx} / \mathrm{calcium}$ phosphate $(\mathrm{CaP})$ can induce excessive ROS production in 

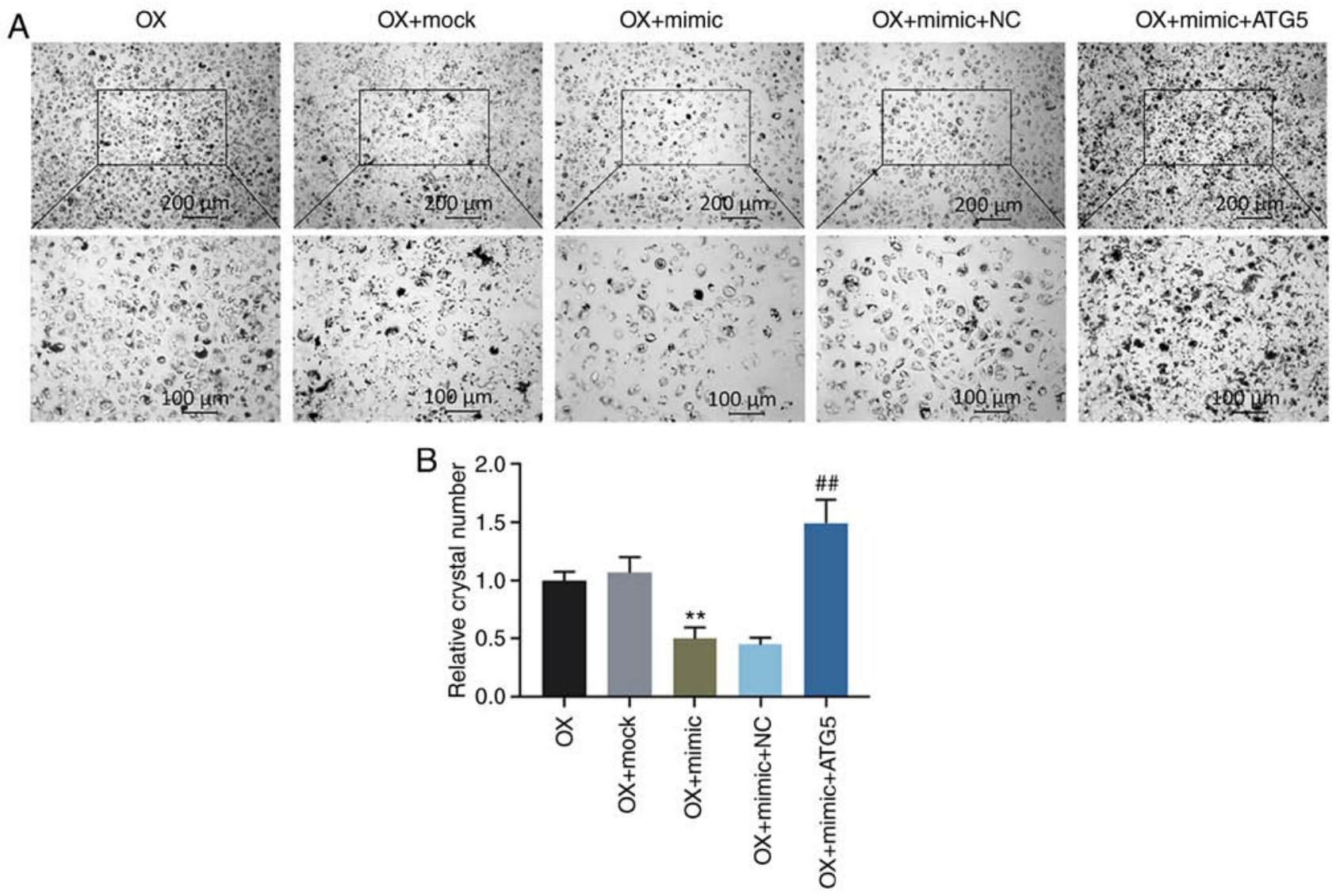

Figure 6. Effects of miR-30c-5p on CaOx crystal adhesion to HK-2 cells. (A and B) Crystal-cell adhesion assay results and quantitative data for crystals adhering to cells treated as described above. Black speckles in (A) indicate the oxalate crystals. Original magnification, $\mathrm{x} 200$. ${ }^{* * *} \mathrm{P}<0.001 \mathrm{vs}$. OX + mock; ${ }^{\# \#} \mathrm{P}<0.001$ vs. OX + mimic + NC. OX, incubation with oxalate; OX + mock, incubation with oxalate and transfection reagent; OX + mimic, co-incubation with oxalate and miR-30c-5p mimic; oxalate + mimic $+\mathrm{NC}$, co-incubation with oxalate, miR-30c-5p mimic and empty plasmid; OX + mimic + ATG5, co-incubation with oxalate, miR-30c-5p mimic and ATG5 overexpression plasmid.

renal epithelial cells (32). ROS are an important parameter involved in oxidative and endoplasmic reticulum dysfunction of cells (33). Therefore, in this study, the effect of the miR-30c-5p on the ROS level was investigated in HK-2 cells exposed to oxalate. The level of LDH released by cells can indicate cell oxidative damage (34). As a product of lipid peroxidation, MDA can be induced by oxidative stress and reflects the degree of oxidative injury. SOD is an antioxidant enzyme, and is involved in the antioxidant system. CAT can neutralize excessive ROS production and catalyzes $\mathrm{H}_{2} \mathrm{O}_{2}$ into $\mathrm{H}_{2} \mathrm{O}$ and $\mathrm{O}_{2}$ (35). Thus, the levels of LDH, MDA, SOD and CAT were determined, and the results revealed that oxalate causes severe oxidative dysfunction, while miR-30c-5p mimic can relieve such an injury induced by oxalate. Taken together, the findings of this study demonstrated that miR-30c-5p is potentially a critical regulator of sodium oxalate-induced kidney stones, and such a finding was further confirmed by crystal-cell adhesion assay. These results suggested that the overexpression of miR-30c-5p relieves cell cytotoxicity and inhibits the formation of sodium oxalate-induced kidney stones.

miRNAs play important roles in various diseases by targeting and regulating mRNAs. In this study, ATG5 was targeted by miR-30c-5p. There is evidence to indicate that ATG5 is involved in the occurrence and development of cell apoptosis; for example, knocking down ATG5 can alleviate the increase in cell apoptosis and apoptosis-associated protein expression induced by hypoxia and reoxygenation (36). Previous studies have also demonstrated that ATG5 promoted cell apoptosis by activating caspase-8 (37), and that ATG5 is involved in the apoptosis of human cardiomyocytes (38) and colorectal cancer cells (39). The knockdown of ATG5 upregulates the apoptotic cell death of human vaginal epithelial cells (40); moreover, ATG5 suppresses cellular proliferation and induces the apoptosis of DF-1 cells (41). In addition, the inhibition of ATG5 can decrease oxidative stress-based cytotoxicity in osteosarcoma cells (42). The damage to renal tubular cells is a major factor contributing to COM crystal adhesion (43). A previous study demonstrated that the inhibition of the autophagy pathway alleviated the oxidative injury to renal tubular cells and reduced $\mathrm{CaOx}$-induced crystal deposition via the p38 signaling pathway (44). Therefore, as an autophagy-related gene, ATG5 is directly regulated by miR-30c-5p and is involved in renal cell oxidative stress and crystal depositions induced by oxalate. To conclude, in this study, the molecular mechanisms underlying the function of miR-30c-5p in oxalate-induced HK-2 cell injury was examined in in vitro experiments; however, these mechanisms need to be confirmed by future in vivo studies.

In conclusion, this study demonstrates that miR-30c-5p is downregulated in HK-2 cells exposed to oxalate, and that miR-30c-5p mimic can alleviate the oxidative stress, cell 
injury and crystal-cell adhesion caused by a high concentration of oxalate through the regulation of ATG5.

\section{Acknowledgements}

Not applicable.

\section{Funding}

This study was supported by the 2018 Medical Scientific Research Plan Project of Dalian City (1811117).

\section{Availability of data and materials}

The analyzed datasets generated during this study are available from the corresponding author on reasonable request.

\section{Authors' contributions}

$\mathrm{XW}$ and BG made substantial contributions to the conception and design of the study. YZ, SH, HC, CC and LJ were involved in data acquisition, data analysis and interpretation. XW and $\mathrm{BG}$ were involved in the drafting of the article or critically revising it for important intellectual content. All authors have read and approved the final version of the manuscript to be published. All authors agree to be accountable for all aspects of the work in ensuring that questions related to the accuracy or integrity of the work are appropriately investigated and resolved.

\section{Ethics approval and consent to participate}

Not applicable.

\section{Patient consent for publication}

Not applicable.

\section{Competing interests}

The authors declare that they have no competing interests.

\section{References}

1. Stern JM, Moazami S, Qiu Y, Kurland I, Chen Z, Agalliu I, Burk R and Davies KP: Evidence for a distinct gut microbiome in kidney stone formers compared to non-stone formers. Urolithiasis 44 399-407, 2016

2. Worcester EM and Coe FL: Clinical practice. Calcium kidney stones. N Engl J Med 363: 954-963, 2010.

3. Ye Z, Zeng G, Huan Y, Li J, Tang K, Wang G, Wang S, Yu Y, Wang Y,Zhang T, et al: The status and characteristics of urinary stone composition in China. BJU Int: Apr 8, 2019 (Epub ahead of print).

4. Khan SR: Reactive oxygen species as the molecular modulators of calcium oxalate kidney stone formation: Evidence from clinical and experimental investigations. J Urol 189: 803-811, 2013.

5. Ma MC, Chen YS and Huang HS: Erythrocyte oxidative stress in patients with calcium oxalate stones correlates with stone size and renal tubular damage. Urology 83: 510.e9-e17, 2014.

6. Asselman M, Verhulst A, De Broe ME and Verkoelen CF: Calcium oxalate crystal adherence to hyaluronan-, osteopontin-, and CD44-expressing injured/regenerating tubular epithelial cells in rat kidneys. J Am Soc Nephrol 14: 3155-3166, 2003.

7. Miyazawa K, Suzuki K, Ikeda R, Moriyama MT, Ueda Y and Katsuda S: Apoptosis and its related genes in renal epithelial cells of the stone-forming rat. Urol Res 33: 31-38, 2005.
8. Liu Y, Li D, He Z, Liu Q, Wu J, Guan X, Tao Z and Deng Y: Inhibition of autophagy-attenuated calcium oxalate crystal-induced renal tubular epithelial cell injury in vivo and in vitro. Oncotarget 9: 4571-4582, 2017.

9. Taguchi K, Hamamoto S, Okada A, Unno R, Kamisawa H, Naiki T, Ando R, Mizuno K, Kawai N, Tozawa K, et al: Genome-wide gene expression profiling of randall's plaques in calcium oxalate stone formers. J Am Soc Nephrol 28: 333-347, 2017.

10. Yu L, Gan X, Liu X and An R: Calcium oxalate crystals induces tight junction disruption in distal renal tubular epithelial cells by activating ROS/Akt/p38 MAPK signaling pathway. Ren Fail 39: 440-451, 2017.

11. Convento MB, Pessoa EA, Cruz E, da Glória MA, Schor N and Borges FT: Calcium oxalate crystals and oxalate induce an epithelial-to-mesenchymal transition in the proximal tubular epithelial cells: Contribution to oxalate kidney injury. Sci Rep 7: 45740, 2017.

12. Wang B, Wu B, Liu J, Yao W, Xia D, Li L, Chen Z, Ye Z and Yu X: Analysis of altered microRNA expression profiles in proximal renal tubular cells in response to calcium oxalate monohydrate crystal adhesion: implications for kidney stone disease. PLoS One 9: e101306, 2014.

13. Hou J: Lecture: New light on the role of claudins in the kidney. Organogenesis 8: 1-9, 2012.

14. Gong Y, Renigunta V, Himmerkus N, Zhang J, Renigunta A, Bleich $\mathrm{M}$ and Hou J: Claudin-14 regulates renal $\mathrm{Ca}^{++}$transport in response to CaSR signalling via a novel microRNA pathway. EMBO J 31: 1999-2012, 2012.

15. Lan C, Chen D, Liang X, Huang J, Zeng T, Duan X, Chen K, Lai Y, Yang D, Li S, et al: Integrative analysis of miRNA and mRNA expression profiles in calcium oxalate nephrolithiasis rat model. Biomed Res Int 2017: 8306736, 2017.

16. Hu YY, Dong WD, Xu YF, Yao XD, Peng B, Liu M and Zheng JH: Elevated levels of miR-155 in blood and urine from patients with nephrolithiasis. Biomed Res Int 2014: 295651, 2014.

17. Zhang C, Yu S, Zheng B, Liu D, Wan F, Ma Y, Wang J, Gao Z and Shan $Z$ : miR-30c-5p reduces renal ischemia-reperfusion involving macrophage. Med Sci Monit 25: 4362-4369, 2019.

18. Zou YF, Wen D, Zhao Q, Shen PY, Shi H, Zhao Q, Chen YX and Zhang W: Urinary MicroRNA-30c-5p and MicroRNA-192-5p as potential biomarkers of ischemia-reperfusion-induced kidney injury. Exp Biol Med (Maywood) 242: 657-667, 2017.

19. Du B, Dai XM, Li S, Qi GL, Cao GX, Zhong Y, Yin PD and Yang XS: MiR-30c regulates cisplatin-induced apoptosis of renal tubular epithelial cells by targeting Bnip3L and Hspa5. Cell Death Dis 8: e2987, 2017.

20. Gutiérrez-Escolano A, Santacruz-Vázquez E and Gómez-Pérez F: Dysregulated microRNAs involved in contrast-induced acute kidney injury in rat and human. Ren Fail 37: 1498-1506, 2015.

21. Zheng W, Xie W, Yin D, Luo R, Liu M and Guo F: ATG5 and ATG7 induced autophagy interplays with UPR via PERK signaling. Cell Commun Signal 17: 42, 2019.

22. Livak KJ and Schmittgen TD: Analysis of relative gene expression data using real-time quantitative PCR and the 2(-Delta Delta C(T)) method. Methods 25: 402-408, 2001.

23. Manissorn J, Fong-Ngern K, Peerapen $\mathrm{P}$ and Thongboonkerd V: Systematic evaluation for effects of urine $\mathrm{pH}$ on calcium oxalate crystallization, crystal-cell adhesion and internalization into renal tubular cells. Sci Rep 7: 1798, 2017.

24. Abhishek A, Benita S, Kumari M, Ganesan D, Paul E, SasikumarP, Mahesh A, Yuvaraj S, Ramprasath T and Selvam GS: Molecular analysis of oxalate-induced endoplasmic reticulum stress mediated apoptosis in the pathogenesis of kidney stone disease. J Physiol Biochem 73: 561-573, 2017.

25. Fishman AI, Green D, Lynch A, Choudhury M, Eshghi M and Konno S: Preventive effect of specific antioxidant on oxidative renal cell injury associated with renal crystal formation. Urology 82: 489.e1-e7, 2013.

26. Cheraft-Bahloul N, Husson C, Ourtioualous M, Sinaeve S, Atmani D, Stévigny C, Nortier JL and Antoine MH: Protective effects of pistacia lentiscus L. fruit extract against calcium oxalate monohydrate induced proximal tubular injury. J Ethnopharmacol 209: 248-254, 2017.

27. Zhao Y, Yin Z, Li H, Fan J, Yang S, Chen C and Wang DW: MiR-30c protects diabetic nephropathy by suppressing epithelial-to-mesenchymal transition in $\mathrm{db} / \mathrm{db}$ mice. Aging Cell 16: 387-400, 2017.

28. Davalos M, Konno S, Eshghi M and Choudhury M: Oxidative renal cell injury induced by calcium oxalate crystal and renoprotection with antioxidants: A possible role of oxidative stress in nephrolithiasis. J Endourol 24: 339-345, 2010. 
29. Jeong BC, Kwak C, Cho KS, Kim BS, Hong SK, Kim JI, Lee C and Kim HH: Apoptosis induced by oxalate in human renal tubular epithelial HK-2 cells. Urol Res 33: 87-92, 2005.

30. Liu X, Li M, Peng Y, Hu X, Xu J, Zhu S, Yu Z and Han S: miR-30c regulates proliferation, apoptosis and differentiation via the Shh signaling pathway in P19 cells. Exp Mol Med 48: e248, 2016.

31. Khan SR: Hyperoxaluria-induced oxidative stress and antioxidants for renal protection. Urol Res 33: 349-357, 2005.

32. Khan SR: Reactive oxygen species, inflammation and calcium oxalate nephrolithiasis. Transl Androl Urol 3: 256-276, 2014.

33. Liang Y, Dong B, Pang N and Hu J: ROS generation and DNA damage contribute to abamectin-induced cytotoxicity in mouse macrophage cells. Chemosphere 234: 328-337, 2019.

34. Ren J, Yuan L, Wang W, Zhang M, Wang Q, Li S, Zhang L and Hu K: Tricetin protects against 6-OHDA-induced neurotoxicity in Parkinson's disease model by activating Nrf2/HO-1 signaling pathway and preventing mitochondria-dependent apoptosis pathway. Toxicol Appl Pharmacol 378: 114617, 2019.

35. Zhao J, Zhang M, Zhang W, Liu F, Huang K and Lin K: Insight into the tolerance, biochemical and antioxidative response in three moss species on exposure to BDE-47 and BDE-209. Ecotoxicol Environ Saf 181: 445-454, 2019.

36. Zhang C, Zhang C, Wang H, Qi Y, Kan Y and Ge Z: Effects of miR-103a-3p on the autophagy and apoptosis of cardiomyocytes by regulating Atg5. Int J Mol Med 43: 1951-1960, 2019.

37. Young MM, Takahashi Y, Khan O, Park S, Hori T, Yun J, Sharma AK, Amin S, Hu CD, Zhang J, et al: Autophagosomal membrane serves as platform for intracellular death-inducing signaling complex (iDISC)-mediated caspase- 8 activation and apoptosis. J Biol Chem 287: 12455-12468, 2012.

38. Zhao P, Zhang BL, Liu K, Qin B and Li ZH: Overexpression of miR-638 attenuated the effects of hypoxia/reoxygenation treatment on cell viability, cell apoptosis and autophagy by targeting ATG5 in the human cardiomyocytes. Eur Rev Med Pharmacol Sci 22: 8462-8471, 2018.
39. Zheng Y, Tan $\mathrm{K}$ and Huang H: Long noncoding RNA HAGLROS regulates apoptosis and autophagy in colorectal cancer cells via sponging miR-100 to target ATG5 expression. J Cell Biochem 120: 3922-3933, 2019.

40. Shroff A and Reddy KVR: Autophagy gene ATG5 knockdown upregulates apoptotic cell death during Candida albicans infection in human vaginal epithelial cells. Am J Reprod Immunol 80: e13056, 2018

41. Liao Z, Dai Z, Cai C, Zhang X, Li A, Zhang H, Yan Y, Lin W, Wu Y, Li H, et al: Knockout of Atg5 inhibits proliferation and promotes apoptosis of DF-1 cells. In Vitro Cell Dev Biol Anim 55: 341-348, 2019.

42. Hollomon MG, Gordon N, Santiago-O'Farrill JM and Kleinerman ES: Knockdown of autophagy-related protein 5 , ATG5, decreases oxidative stress and has an opposing effect on camptothecin-induced cytotoxicity in osteosarcoma cells. BMC Cancer 13: 500, 2013

43. Khan SR: Renal tubular damage/dysfunction: Key to the formation of kidney stones. Urol Res 34: 86-91, 2006.

44. Duan X, Kong Z, Mai X, Lan Y, Liu Y, Yang Z, Zhao Z, Deng T, Zeng T, Cai C, et al: Autophagy inhibition attenuates hyperoxaluria-induced renal tubular oxidative injury and calcium oxalate crystal depositions in the rat kidney. Redox Biol 16: 414-425, 2018.

This work is licensed under a Creative Commons Attribution-NonCommercial-NoDerivatives 4.0 International (CC BY-NC-ND 4.0) License. 